\title{
A INTERPRETAÇÃO TOMISTA DA FÍSICA DE ARISTOTELES.
}

M. AMELIA M. DANTES

Disciplina: História das Ciências.

O pensamento antigo não se perdeu completamente no Ocidente, permanecendo pela Alta Idade Média uma coleção de fragmentos de filósofos gregos e romanos que se transmitiram por enciclopédias como as de Boécio (480-524 dC), Isidoro de Sevilha (560-636 dC), Cassiodoro (490-580 dC) e Beda (673-735 dC).

No século IX, com o reatamento comercial do Ocidente com o Oriente, começaram a chegar à Europa textos inéditos que haviam sido preservados, assimilados e criticados pelos pensadores árabes. As cidades italianas voltadas para o comércio foram as primeiras cidades européias a entrar em contato com estes textos, porem, a sua difusão só se deu depois da tomada de Toledo pelos cruzados em 1085 e da Sicília em 1091.

$\mathrm{O}$ número extraordinário de obras traduzidas do árabe para o latim, nos séculos XIl e XIIl, testemunha o entusiasmo com que o mundo ocidental recebeu os textos greco-árabes. Já por 1250, estava assimilado quase tudo o que se transmitira pela Espanha e sul da Itália .

As obras que foram traduzidas neste período compreendiam principalmente textos de filosofia e filosofia natural.

\section{A redescoberta da obra de Aristóteles.}

Da extensa obra de Aristóteles, até o século XII, era conhecida na Europa apenas a primeira parte do tratado de lógica, o Organum, em tradução de Boécio. Este texto passou a ser conhecido como a logica vetus quando, por volta de 1250 , a tradução latina da logica nova tornou conhecida a parte final do Organum.

Ainda no século XII alguns textos filosóficos de Aristóteles tornaram-se conhecidos, por meio de traduções feitas diretamente do 
grego. Porem, as traduções mais difundidas foram as de Gerardo de Cremona e as de Miguel Escoto, do início do século XIII, que eram traduções de textos árabes, que por sua vez eram traduções de versões siríacas da obra original. Neste processo os textos aristotélicos sofreram deformações, tendo sido transmitida uma fusão da filosofia aristotélica com a filosofia dos neoplatônicos árabes. $O$ interesse pelos textos aristotélicos puros motivou uma segunda etapa de traduções. Guilherme de Moerbeke, de 1260 a 1271, fez uma revisão das traduções existentes, partindo de manuscritos gregos. No último quarto do século XIII, já era conhecida praticamente toda a obra de Aristóteles.

A reação à entrada dos textos aristotélicos foi diversificada. Ao mesmo tempo em que os intelectuais se entusiasmavam com a riqueza contida nestes textos, um clima de apreensão crescia na Europa.

Havia razões para esta apreensão: de um lado a redescoberta das obras de Aristóteles e de outros pensadores gregos como Euclides, mostrava a riqueza dos sistemas construidos racionalmente. Já no século XII, os dialéticos embrenhavam-se pela sofística. Santo Anselmo e Fulberto pregavam o uso da dialética como a forma mais eficaz de se chegar à verdade, gerando temores em relação à pretensão de se incorporar a dialética à Teologia .

Alem disso, os textos aristotélicos apresentavam idéias, como a da eternidade do mundo, que estavam em oposição ao pensamento cristão. Estas idéias foram em parte modificadas por alguns comentadores neoplatônicos árabes, como Avicena. Porem, na obra de Averróes, cujos comentários sobre a obra de Aristóteles foram traduzidos para o latim no início do século XIII por Miguel Escoto, o aristotelismo era apresentado mais puro, o que tornava mais críticas as contradiçōes.

Devido à amplitude do problema, já que foi grande a receptividade à obra de Aristóteles, não tardaram medidas oficiais do Papado, no sentido de limitar a transmissão da obra de Aristóteles.

A proibição de 1210 testemunha a apreensão da Igreja. Neste ano, o conselho provincial de Paris, então o mais importante centro de ensino teológico e reduto dos dialéticos, proibiu, sob pena de excomunhão, o ensino público ou privado dós textos aristotélicos de filosofia natural ou seus comentários.

Porem, se uma parte do clero se orientou para uma repulsa à obra de Aristóteles e uma valorização do misticismo, houve paralelamente a preocupação pela incorporação do aristotelismo ao Cristianismo, com a Teologia enriquecida pelas formas de pensamento racional. 
Pela segunda década do século XIII, no entanto, a posição oficial da Igreja continuou sendo de repulsa à obra filosófica de Aristóteles. Os estatutos da Universidade de Paris, sancionados em 1215 só autorizavam o ensino do Organum, proibindo o ensino da Metaphysica, da Physica e outras obras de filosofia natural e de seus comentadores, como David de Dinant e Amalrico de Bena.

Porem, a proibição não conseguiu barrar a corrente que se desenvolvia, tanto que em 1228 Gregório IX dirigiu-se especialmente aos professores de Teologia de Paris, chamando a atenção para os abusos da Filosofia e reiterando a crença em que a Teologia estava alem da razão humana.

Uma mudança de atitude já transpårece numa mensagem do próprio Gregório IX, em 1231, em que esclarece que o ensino da Physica permaneceria proibido, até que este texto fosse submetido à censura e purgado de seus erros. Poucos dias depois Gregório IX já nomeava uma comissão que deveria fazer uma revisão da filosofia natural aristotélica, a fim de torna-la utilizavel no ensino. Este ato iniciou uma nova fase, em que o Papado incentivou os magistri para o comentário do corpus aristotélico, tendo em vista sua assimilação ao pensamento cristão.

Entre 1240 e 1248, Alberto Magno (1206 ou 1207-1280) fez cinco comentários das obras de filosofia natural de Aristóteles, quando ainda era proibido tratar destas obras nas escolas parisienses. Ainda mais: Alberto Magno utilizou extensamente os comentários de Averróes, apesar das críticas que eram feitas ao aristotelismo averroista.

O franciscano Rogério Bacon (1210, 1214?-1294), então tambem na Universidade de Paris, foi outro teólogo que se dedicou ao comentário da filosofia natural aristotélica.

Porem, foi na obra de São Tomás de Aquino (1225-1274) que se atingiu o ápice deste trabalho de assimilação da filosofia aristotélica à Teologia. Seus comentários mostram a preocupação de demonstrar a afinidade das idéias aristotélicas e o pensamento cristão, chegando à concepção de sínteses teológicas .

Esta fase de assimilação da obra de Aristóteles tem seu ponto alto em 1255, quando os novos estatutos da Universidade de Paris liberaram à especulação filosófica os escritos de lógica, estética, metafísica e filosofia natural.

Já em 1277, uma condenação levantada por Etienne Tempier, chanceler da Universidade de Paris, proibia 219 teses, em sua maioria averroistas, o que atingia principalmente Siger de Brabante. Porem, 20 das teses eram tomistas, o que mostra uma reação do Papado à 
obra de harmonização do aristotelismo ao Cristianismo. Uma reafirmação dos princípios tomistas só se deu no fim do século XIX, com Leão XIII declarando ser o Tomismo a Filosofia oficial da Igreja.

\section{O comentário dos 8 livros da "Física" por São Tomás de Aquino.}

O trabalho sobre textos, em forma de comentários, foi extensamente utilizado pelos intelectuais do século XIII. Chenu (1) considera mesmo que o comentário foi o gênero de base da renascença cultural então ocorrida.

São Tomás dedicou-se extensamente a comentários de obras de autores gregos ou árabes, como Boécio, Amônio, Proclo, Pseudo-Dionísio, Temístio, Avicena, Averróes. Porem, seu interesse de comentarista se voltou mais para os textos de Aristóteles, que comentou em sua totalidade (2).

Os comentários tomistas de textos aristotélicos se caracterizam por uma procura constante da intentio Aristotelis (3), que segundo São Tomás havia sido deturpada pelos outros comentadores. Esta preocupação de expor as idéias de Aristóteles sem deformações, fez com que São Tomás optasse por comentários de tipo literal.

A figura mais constantemente visada em suas críticas é mesmo Averróes, cujos comentários haviam tido grande aceitação no Ocidente. São Tomás se refere depreciativamente em relação aos averroistas:

"Estas pessoas preferem errar em companhia de Averróes, do que partilhar uma ciência exata com os outros peripatéticos; Averióes, entretanto, foi menos um peripatético que o corruptor da filosofia peripatética" (4).

(1). - M. D. Chenu, Introduction a l'étude de St. Thomas d'Aquin (Montreal, Publications de l'Institut d'études médievales, 1954), p. 176.

(2). - São comentários de São Tomás sobre textos de Aristóteles: In perihermenian (até a II, 2); In posteriores analyticorum, In VIII libros physicorum, In VIl libros de caelo et mundo (até III, 8), In II libros de generatione et corruptione (até I, 17), In IV livros meteorum (até II, 10), In III libros de anima, In librum de sensu et sensato, On librum de memoria et reminiscentia, In XII libros Metaphysicorum, In X libros Ethicorum e In libros Politicorum (até III, 6).

(3). - P. Moraux et al., "Les sources de St. Thomas" artigo de D. A. Callus in Aristote et St. Thomas d'Aquin (Paris, Ed. Béatrice, 1967), p. 98. p. 536 .

(4). - P. Duhem, Le systeme du monde, vol. V (Paris, 1973-1917), 
Apesar disso, foi grande a atração de São Tomás pelo filósofo árabe, cuja presença permanece em toda a obra tomista. e 1269 (5).

O comentário sobre a "Física" parece ter sido escrito entre 1268

O comentário é extremamente esquematizado. Como as leituras se desenvolvem em geral sobre um tema determinado, o primeiro parágrafo de cada leitura apresenta uma subdivisão do tema em suas partes, com subdivisões secundárias quando necessário. $O$ tema $\mathrm{em}$ questão é analisado minuciosamente em seus elementos. Isto faz com que, já de início, o leitor tenha uma visão geral do que Aristóteles vai tratar. Este comportamento analítico faz com que o comentário seja extremamente árido, já que os valores estéticos são preteridos nesta procura por uma apresentação objetiva do texto aristotélico.

São Tomás utilizou todo o seu conhecimento do corpus aristotélico para tornar mais claro o texto, em geral muito conciso, de Aristóteles. Sua familiaridade com a obra do Filósofo fịca patenteada por todo o comentário.

Porem, se São Tomás torna mais claro, com seu comentário, o texto aristotélico, por outro lado não põe em dúvida os princípios básicos da física aristotélica. Sua física é aristotélica e mesmo os exemplos que utiliza para esclarecer o texto, enquadram-se perfeitamente nos princípios da filosofia natural aristotélica.

Somente em pontos em que o desenvolvimento lógico do estudo do movimento leva Aristóteles a conclusões que estão em oposição a crença cristã, é que as idéias do comentador aparecem. Estes pontos contraditórios da Física de Aristóteles já haviam sido levantados em sua maior parte, principalmente pelos comentadores árabes. Avicena, pela sua posição neoplatonizante não levantou tantas contradições como Averróes, que se aproximou muito mais do pensamento aristotélico puro, pondo a claro os pontos em que a filosofia aristotélica entrava em choque com o pensamento cristão.

A crítica que São Tomás fez a Averróes e a presença constante do filósofo árabe no comentário, mostram que um dos objetivos de São Tomás neste texto, foi de refutar as contradições levantadas por Averróes, mostrando assim a harmonia entre a filosofia aristotélica e a Teologia .

(5) . - St. Thomas d'Aquin, Commentary on Aristotle's Physics (Londres, Routledge \& Kegan Paul, 1963), p. XXI, introd. de V. J. Bourke. 
Nos três primeiros livros da Física, Aristóteles trata do embasamento conceitual e metodológico da filosofia natural. O comentário destes livros trata mais de um esclarecimento do exposto, sem que o comentador ponha em dúvida o exposto.

Mesmo nos livros $4 .^{\circ}, 5 .^{\circ}, 6 .^{\circ}$ e $7 .^{\circ}$, em que Aristóteles trata de problemas mais específicos em relação ao estudo do movimento, são poucos os pontos polêmicos. Em geral São Tomás procura esclarecer as interpretações feitas por comentadores anteriores, como quando no comentário do livro $4 .^{\circ}$, São Tomás refuta a interpretação averroista do movimento da primeira esfera, concluindo pela validade da interpretação de Temístio (6).

É no livro $8 .^{\circ}$ que estão contidos os trechos mais polêmicos do comentário e isso justamente pelo fato de ser neste livro que Aristóteles trata dos limites do real: sobre o ponto inicial ou final do tempo e do movimento ou sobre o Primeiro Motor.

Vejamos alguns destes pontos:

\section{- a eternidade do movimento.}

No $1 .^{\circ}$ capítulo do livro $8 .^{\circ}$ da Física, Aristóteles postula a eternidade do movimento, que ele prova por 3 argumentos: um primeiro fundado sobre a definição do movimento, um segundo sobre a noção de movimento e um terceiro sobre a eternidade do tempo.

Iniciando o primeiro argumento, em um trecho compreendido entre $251 \mathrm{a} 8$ e $251 \mathrm{a} 15$ (notação Bekker), Aristóteles diz:

“... o movimento é a enteléquia do movel enquanto movel. E portanto necessário que existam primeiramente as coisas que tem o poder de mover segundo cada movimento ..." (7).

O texto de Aristóteles é obscuro e Averróes no seu comentário extrapola o argumento de Aristóteles para o primeiro agente universal, força ativa da totalidade do ser, tocando assim na própria Criação: a matéria primeira seria anterior à Criação, já que a própria Criação seria uma forma de movimento. Portanto, a matéria primeira não teria sido criada por Deus, o que se opõe à concepção agostiniana da Criação .

No seu comentário São Tomás procura mostrar que Averróes interpretou mal o texto aristotélico, utilizando outros textos do corpus aristotélico. Este ponto São Tomás consegue esclarecer pela afirma-

(6). - Idem, ibidem, p. 214 e seg. p. 102

(7). - Áristote, Physique (Paris, Les belles lettres, 1952), vol. 2, 
ção de Aristóteles na Metafísica II, de que a matéria tambem é derivada do primeiro princípio do ser (9).

Este é um trecho bem característico deste comentário de São Tomás, que mostra sua fidelidade ao aristotelismo, partindo dele para refutar interpretações de filósofos anteriores.

- Ainda no capítulo 1 do livro $8 .^{\circ}$, aparece um outro ponto controvertido, tambem ligado ao problema da Criação. Corresponde ao trecho que vai de $251 \mathrm{a} 10$ a $251 \mathrm{~b} 28$, em que Aristóteles desenvolve a terceira prova da eternidade do movimento, baseada na eternidade do tempo. O argumento de Aristóteles para provar a eternidade do tempo é o seguinte: como o instante é um começo e um fim, começo do tempo futuro e fim do tempo passado, então necessariamente o tempo existiu sempre. Se é assim para o tempo, será tambem para o movimento, já que o tempo é uma manifestação do movimento (10). Este argumento leva a conclusões que são frontalmente contra o pensamento cristão e São Tomás procura esclarece-lo.

A sua refutação do argumento aristotélico é brilhante, partindo da observação de que a definição que Aristóteles dá para o tempo é tendenciosa, o que a faz necessariamente levar à conclusão esperada. No parágrafo 983 do seu comentário São Tomás ressalta a analogia entre a relação instante-tempo e a ponto-reta, analogia que o próprio Aristóteles utiliza no livro $6 .^{\circ}$ da Física. Neste livro o Filósofo afirma que o ponto geométrico é um começo e um fim, somente se for parte de uma linha infinita, o que leva São Tomás a concluir que Aristóteles, na demonstração sobre a eternidade do tempo, pressupôs de início esta eternidade, quando queria prova-la. Alem disso, São Tomás chama a atenção para o fato de que a concepção cristã da Criação como um começo do tempo, não entra em choque com a definição aristotélica de que todo o instante é um começo e um fim, já que o instante primeiro sendo tal que antes dele não existia tempo, alem de ser um início, é tambem um fim, o fim do tempo não existente (11). Assim, a definição aristotélica do instante não leva necessariamente à eternidade do tempo, podendo ser mantida paralelamente à idéia de Criação.

Vem completar a visão tomista da Física aristotélica, a parte do comentário correspondente ao texto que vai de $251 \mathrm{~b} 28$ a $252 \mathrm{a} 5$, em

(8). - St. T. Aquinas, Op. cit., pp. 475 e 476.

(9). - Idem, ibidem, p. 476.

(10). - Aristote, Op. cit., p. 104.

(11). - St. T. Aquinas, Op. cit., p. 482. 
que o Filósofo prova a eternidade do movimento. $\mathrm{O}$ argumento usado por Aristóteles é o mesmo usado anteriormente, para provar a eternidade do tempo: de um encadeamento de movimentos, se chega à impossibilidade de um limite no passado remoto, o movimento sempre existiu e sempre existirá. Este argumento é construido essencialmente pelo raciocínio, partindo de considerações sobre o movimento como existe na Natureza.

Se os comentadores anteriores procuravam transformar esta prova aristotélica, procurando colocar o texto em acordo com as verdades da fé, São Tomás aceita completamente a prova ariatotélica, dizendo que o texto expressava exatamente as idéias do autor, sendo tambem correto o raciocínio empregado. Se Aristóteles chega a uma conclusão falsa é simplesmente porque suas considerações se referem a uma concepção da Natureza como sendo regida apenas por leis naturais. Porem, esta não é uma concepção cristã da Natureza, já que o ato da Criação dos corpos por Deus não se enquadra no que se chama processo natural, pois Deus age pela Sua vontade e não pela natureza.

Esta parte do comentário é muito significativa, pois mostra, num ponto de impasse, a posição de São Tomás: como Aristóteles foi um filósofo não cristão, é compreensivel que em sua obra apareçam concluões opostas às crenças cristãs, já que se trata de uma concepção cósmica distinta. Se vimos anteriormente, nas críticas à Averroés, São Tomás fiel ao aristotelismo, vemos aqui mais claramente sua posição frente à filosofia aristotélica: ela deve ser aceita quando não vai contra o testemunho do Evangelho. No caso de uma oposição é ao Evangelho que o cristão deve se prender.

\section{- sobre o Primeiro Motor.}

No final do livro $8 .^{\circ}$ da Física, Aristóteles conclui que necessariamente há um Primeiro Motor, que é infinito e uno. Na Metafísica se completa a concepção deste Primeiro Motor, responsavel pelo movimento da primeira esfera celeste: o Primeiro Motor é uma substância eterna e imovel, separada dos seres, indivisivel e divina (12). Encontram-se assim no corpus aristotélico, se bem que não especificamente na Física, os elementos para a extrapolação tomista de que existe necessariamente o Primeiro Motor, que pelos seus atributos só pode ser Deus:

"E então o Filósofo termina sua điscussão geral sobre as coisas naturais com o primeiro princípio de toda a Natureza, que está sobre todas as coisas, Deus, abençoado para sempre, Amem" (13).

(12). - Apud. R. Mondolfo, $O$ pensamento antigo, vol. 2 (São Paulo, Ed. Mestre Jou, 1964-5), p. 40 e 41.

(13). - St. T. Aquinas, Op. cit., p. 592. 
Esta prova da existência de Deus encontra-se já na obra de Alberto Magno e foi incorporada por São Tomás à Suma Teológica, questão II, art. II, quando São Tomás coloca que a existência de Deus é demonstravel a partir dos efeitos que conhecemos (14).

São 5 as provas que São Tomás apresenta, da existência de Deus. A primeira é a aristotélica da existência do Primeiro Motor (15). Era a preferida por São Tomás que a qualificava de prima et manifestior via. Segundo Paulus (16), esta preferência se devia à acessibilidade desta prova à razão.

\section{Conclusões.}

A análise deste comentário de São Tomás de Aquino sobre a Física de Aristóteles, nos revela que o que norteia o texto é a preocupação do teólogo Tomás, por questões de filosofia natural. Isto quer dizer que o interesse pelo estudo do movimento existe, na medida em que esteja relacionado à ciência das coisas divinas. E neste comentário, se bem que São Tomás esteja constantemente preocupado no esclarecimento do texto aristotélico, seu interesse está acima de tudo no esclarecimento das oposições existentes entre a filosofia natural aristotélica e o pensamento cristão.

O esclarecimento destes pontos de atrito se fazia necessário, já que as contradições haviam se tornado mais agudas nos comentários dos filósofos árabes. Não foi por acaso que as constantes proibições decretadas quanto ao ensino e divulgação dos textos aristotélicos, se referia sempre aos textos de filosofia natural. Eram justamente estes textos que continham estes pontos contraditórios.

São Tomás, como escolástico, procurou resolver as contradições por meio do raciocínio, utilizado sempre de forma rigorosa. Porem, esta independência da dialética não é total, o que aparece bem claramente neste comentário sobre a Física: a verdade é uma só; portanto, o homem deve chegar racionalmente a resultados em harmonia com a crença cristã. No referente à conceituação básica da Física, São Tomás é totalmente aristotélico: sua física é aristotélica. Porem aqui tambem o aristotelismo de São Tomás se mantem enquanto não entra em choque com o pensamento cristão. Como diz Duhem (16), São Tomás não se importava de ser infiel ao aristotelismo, já que a Filosofia de-

(14). - S. Tomás, Suma Teológica (São Paulo, Ed. Fac. Fil. Sedes Sapientiae, 1944), p. 68 .

(15). - Idem, ibidem, p. 72 a 79.

(16). - P. Duhem, Op. cit., p. 560. 
via se subordinar à Teologia. A tarefa a que São Tomás se propõe é mesmo a de cristianizar o aristotelismo.

Por outro lado aos poucos a epistemologia aristotélica foi substituindo a platônica, trazendo a idéia de que se deve partir do sensivel para se chegar ao conhecimento. Esta nova conceituação metodológica penetra na própria experiência religiosa, já que os objetos sensíveis guardam sinais da natureza divina e são assim ponto de partida para a experiência religiosa. E a partir desta nova concepção epistemológica que deve ser compreendida a aquisição, pela Teologia, da primeira prova da existência de Deus, a prova aristotélica da existência do Primeiro Motor.

MARIA AMELIA MASCARENHAS DANTES. - Nascida em São Paulo, Estado de São Paulo. Bacharel em Física pela Faculdade de Filosofia, Ciências e Letras da Universidade de São Paulo (1964). Doutora em Ciências pela Faculdade de Filosofia, Letras e Ciências Humanas da Universidade de São Paulo (1973). Professora Assistente-Doutora do Departamento de História da Faculdade de Filosofia, Letras e Ciências Humanas da Universidade de São Paulo. Atualmente estagiando no Instituto de História da Ciência de Sorbonne, França.

Principais Trabalhos:

Sobre a Medicina de Paracelso (tese de doutoramento). ed. mimeografada.

Da Alquimia à Química Moderna in História da Ciência e Perspectiva Científica, coleção da Revista de História, n 46, 1974.

Física Auto-Instrutiva, em colaboração, 5 vols.

Um Estudo do Comentário de São Tomás de Aquino Sobre a Física de Aristóteles, Ciência e Cultura, vol. 25, n० 6, 1972.

(Sobre) a História das Invenções Mecânicas de Usher, Revista de História, vol. 51, n⿳ 102, 1975. 